\title{
INCREASING SYSTEM UNDERSTANDING AND MOTIVATION IN Students Using Novel INTERACTIVE Learning Methods
}

\author{
Ilyas Mattmann \\ Institute of Product Development and Machine Elements, TU Darmstadt \\ mattmann@pmd.tu-darmstadt.de
}

\begin{abstract}
Undergraduate engineering design students face the challenge of proving the durability of complex mechanical systems. Students are burdened with an excess of existing information. The key challenge lies in making a dry subject interesting to undergraduate students to increase fundamental skills and motivate students towards self-determined learning.

This paper presents a newly developed didactic approach that uses interactive learning methods for courses with large student numbers to increase learning success. The novel learning concept focuses on improving student motivation using interactive learning methods to achieve the intended learning outcomes and promote selfdetermined learning. Learning methods within the interactive learning concept are applied to prove the durability of welded joints.

The paper highlights experiences from teaching practice gained while using these novel interactive learning methods in large engineering courses of more than 900 undergraduate engineering design students.
\end{abstract}

Keywords: Interactive learning methods : Courses with large student numbers : Increasing motivation : Open source online systems : Novel teaching concept

\section{INTRODUCTION}

Proving the durability of complex mechanical systems is a difficult task for undergraduate mechanical and process engineering students. They have to deal with a variety of technical standards to prove that mechanical systems can withstand strain.

For example, the durability of welded joints has to be calculated in Europe using the EUROCODE program (DIN EN ISO 1993-1; parts 1, 8 and 9), which provides more than 350 pages of theoretical information about calculation methods and formula for welded joints, DIN EN ISO 2553, and the huge variety of guidelines related to different welding processes, as partly shown in Table 1 .
Table 1: European standards for proving the durability of welded joints

\begin{tabular}{|c|c|}
\hline Technical standard & Content \\
\hline DIN EN 1993-1-1 & - $\quad$ Design of steel structures \\
\hline DIN EN 1993-1-8 & $\begin{array}{ll}- & \text { Design of joints } \\
\text { - } & \text { Proving durability of } \\
& \text { welded joints under } \\
& \text { predominantly static stress }\end{array}$ \\
\hline DIN EN 1993-1-9 & $\begin{array}{ll} & \text { Fatigue } \\
\text { - } & \text { Proving durability of } \\
\text { welded joints under } \\
\text { predominantly dynamic } \\
\text { stress }\end{array}$ \\
\hline DIN EN ISO 2553 & $\begin{array}{ll}- & \text { Symbolic representation } \\
\text { through drawings - Welded } \\
\text { joints }\end{array}$ \\
\hline
\end{tabular}

Undergraduate engineering design students have to combine knowledge of mechanics, material science and process engineering to prove the durability of complex mechanical systems, as shown in Figure 1.

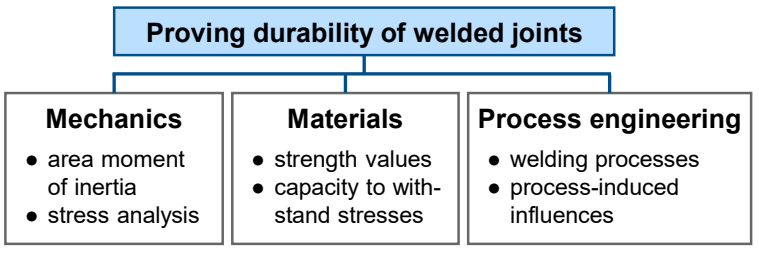

Fig. 1. Necessary knowledge for complex calculations of welded joints

Undergraduate students are burdened with excess volumes of information, causing many students to get lost on the way to achieving specified learning outcomes. They passively consume presented teaching content in auditorium exercises.

Learning success is predominantly achieved by students that are motivated by active participation to critically reflect on their current knowledge [1,2], according to the motivation theory of DECY and RYAN [3] (Section 2). 
This paper presents a newly developed didactic approach (Section 3) that uses interactive learning methods for courses with large student numbers to increase learning success. The main challenge to the newly developed learning concept exercises is the large classrooms containing hundreds of students.

The novel learning concept focuses on improving student motivation using interactive learning methods (Section 4) to achieve the intended learning outcomes and promote self-determined learning [3].

This paper highlights the experience of using these novel interactive learning methods in large courses with more than 900 attending undergraduate students (Section $5)$.

\section{USE OF MOTIVATION THEORY FOR NOVEL LEARNING CONCEPTS}

The novel interactive learning concept is based on the motivation theory of DECY and RYAN. This theory proposes a strong correlation between motivation and self-determined learning. It states that extrinsically motivated students develop an intrinsic pattern of motivation, which is experienced by students as selfdetermining [3].

However, learning activities that are intrinsically motivated have an optimal requirements level that is neither a mental underload nor overload for students. Positive feedback in relation to self-acquired content may lead to a further increase in student motivation [3]. This is the application of motivation theory, according to DECY and RYAN.

The main goal of the new learning concept to be developed for exercises in large classrooms is to encourage undergraduate students to actively participate, stimulating the learning process. Undergraduate students should be motivated to continually question complex calculation methods. Increased motivation in undergraduate students should promote self-determined study to gain deeper insights into the calculation methods.

\section{TEACHING CONCEPT USING NOVEL INTERACTIVE LEARNING METHODS}

\subsection{Teaching Challenges in Large Courses}

The following sections address the main teaching challenges that arise in large courses in which complex calculation and mechanical theory is taught to engineering students.

3.1.1 A flood of information. Most students are burdened by the amount of information that is provided in a short time in conventional auditorium exercises. While some students are well-organized and dedicated to their tasks, others feel overwhelmed and under pressure.

Undergraduate students get lost on the way to achieving specified learning outcomes. They get bored and find it hard to identify their individual preferences in the teaching content.

Clearly defined learning outcomes help students find their way through various approaches and calculation methods. Possible obstacles to the learning outcomes must be anticipated in advance in order to avoid them during exercises in large courses. The available teaching material should be reduced to the level of minimum understanding.

3.1.2 Design of teaching material. Teaching materials, such as slides, scripts, worksheets, and exercises, support students in the learning process. The focus is on the presentation and illustration of teaching content. The teaching material for exercises in large courses should be well-structured.

3.1.3 Diversity. Undergraduate students in engineering design are highly diverse, having:

- Varying levels of knowledge from the basic course

- Different ethnic origins

- To repeat the course, completing it for a second time

- Heterogeneous student groups

- Different learning styles

- Physical handicaps

The learning concept should use multiple learning and teaching strategies to deal with diversity in large classrooms of more than 900 undergraduate students.

3.1.4 Activation of students. Most learning concepts in large courses at universities are based on knowledge transfer occurring through the passive reception of students. However, motivation in students to absorb the presented content decreases rapidly. Novel learning strategies, like Flipped Classrooms, are a suitable way to engage students actively in the learning process. Passively consumed teaching content that bores most students during auditorium exercises is outsourced to student selfstudy for preparation and follow-up.

Open source online systems, like PINGO, can be used to elicit classroom feedback, which activates students. PINGO is an acronym for the open source, web-based solution that was developed by the University of Paderborn. It stands for Peer Instructions for very large Groups. In PINGO, students use their mobile devices to answer questions online and in real-time. Lecturers get classroom-response. PINGO facilitates peer instruction by providing a web-based interface for lecturers. It is free of charge and can be used for commercial purposes like 
corporate trainings. However, there must be enough time in auditorium exercises to use activating didactic methods.

These challenges in teaching need a suitable concept that provides students with fun and an understanding of complex calculations, as shown in the following section.

\subsection{Didactic Concept}

The didactic concept using novel interactive learning methods was developed in 2016 for use in auditorium exercises during the Machine Elements and Mechatronics II unit at TU Darmstadt. Typical machine elements in the field of mechanical engineering are taught in lectures, auditorium exercises and group exercises.

Within this system, the stress-tolerant design of bearings, shafts, cross-press braces, key joints, welded joints, screws, springs and dampers is taught. All of these machine elements require durability to be proven according to currently valid technical standards. Conventional exercises in large classes are met with passive attitudes from students. Dry content is presented in a dry manner.

Figure 2 shows the didactic concept using the mentioned learning methods.

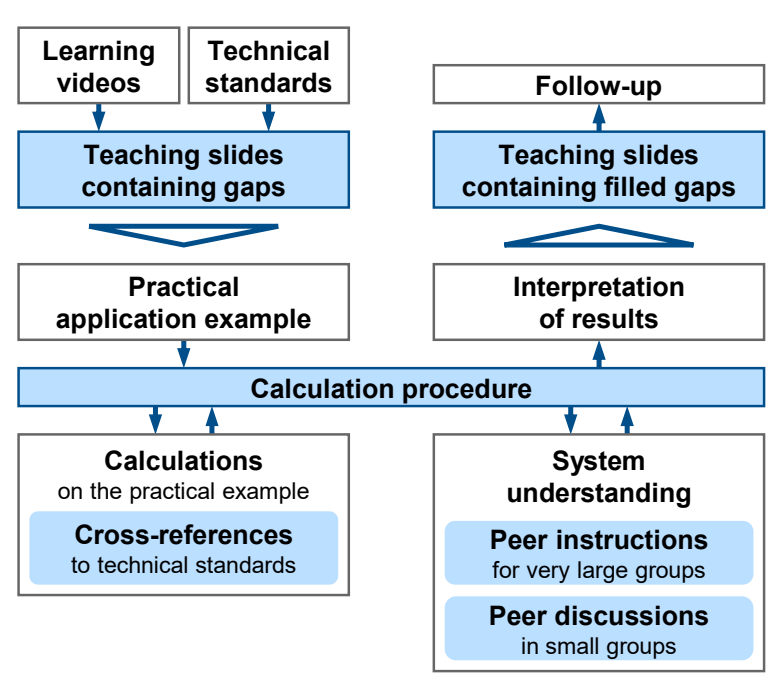

Fig. 2. Model of the learning concept

The novel learning concepts focus on encouraging students to participate actively during relevant parts of the auditorium exercise and to critically reflect on their current understanding of the calculations to answer questions. At this point, the research questions whether existing methods for imparting dry knowledge on the calculation procedure are suited to progressing student study, and how the diverse range of students can be considered.
The aim of the learning concept is to provide students with the essential calculation procedure for proving durability of welded joints as well as practical application examples. Figure 3 shows the general calculation procedure for proving the durability of welded joints.

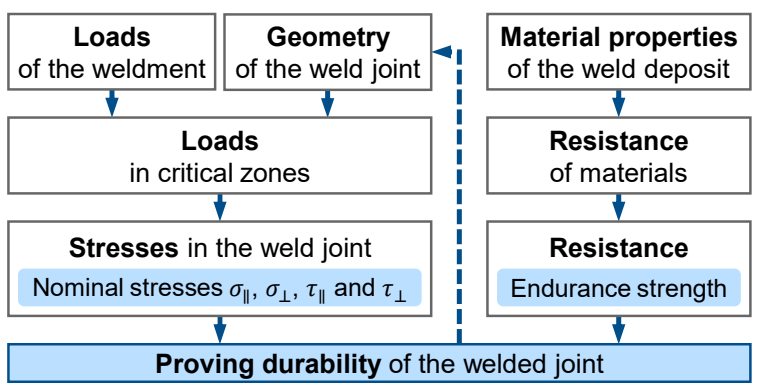

Fig. 3. General calculation procedure for proving the durability of welded joints

Application examples, like a gusset plate (Figure 4), serve as easily understandable and illustrative technical systems for students to perform calculations and develop a system understanding of the calculation procedure.
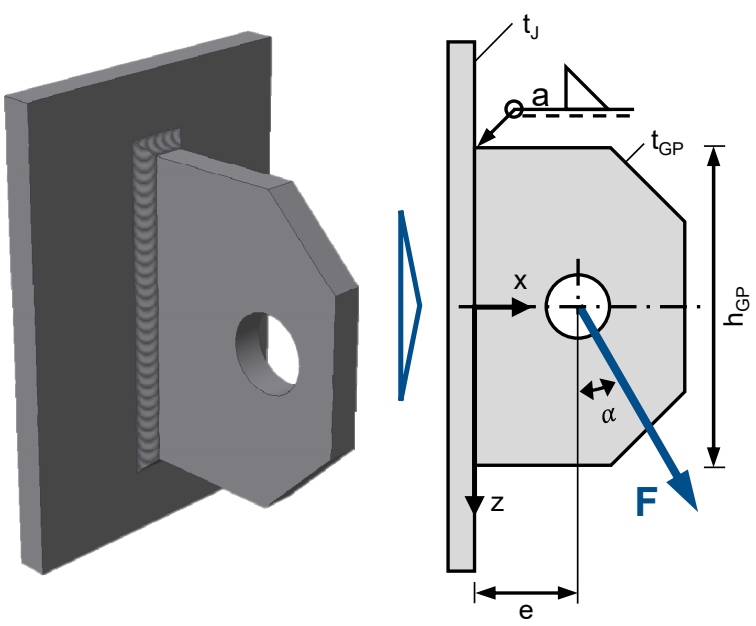

Fig. 4. Gusset plate as practical application example

Students should actively participate, think and reflect on their learning progress within the 90 minutes of the auditorium exercise. Theoretical background information is provided as short learning videos - each with a length of 60 to 90 seconds.

Students should prepare themselves in a self-study phase then discuss difficulties, problems and results during class. The teaching material is characterized by gaps that are designed to be filled during the auditorium exercise.

An open source online system for eliciting classroom feedback is used to motivate students. It is used to 
increase system understanding by initiating web-based selection of answers to questions or getting quick feedback from students. Current knowledge levels should be reflected by these queries. Misunderstood content can be re-examined and corrected in peer discussions to help students find the right answers.

\section{NOVEL INTERACTIVE LEARNING METHODS}

The novel learning concept is based on multiple strategies to address the main teaching challenges that arise in large courses containing hundreds of students.

The learning concept developed combines the following elements:

- Short videos (less than 90 seconds) that graphically explain the model theory behind calculations, preparing students before exercises, according to the inverted classroom model

- Practical application examples during the exercises to solve technical problems in intense discussions with students

- Systematic reduction of teaching material by focusing on the most important calculation steps

- Using web-based solutions that facilitate peer instruction

- Peer discussion to critically reflect on system understanding

- Think-Pair-Share Methods

- Cross-referencing of the technical standards by references in the presentation

- Teaching slides contain gaps, which are interactively completed using a tablet PC during the auditorium exercise so that students comprehend why each of the calculations is done in a particular way at an appropriate speed.

The application of Think-Pair-Share methods in large courses is a highly difficult task. Noise increases significantly during discussions between the undergraduate students. The danger of losing control of the situation increases.

\subsection{Short learning videos}

Learning videos move theoretical contents into the self-study phases. Modern and scientifically designed teaching videos are provided online to students. This enables flexible and diversity-based analysis of the video content. The short teaching videos lead to a targeted reduction of the teaching content in the auditorium exercise. Three teaching videos, each with a length of 90120 seconds, deal with:
- Schematic representation of welded joints in technical drawings

- Geometry of welded joints, including the underlying welded seam model

- Preliminary calculation and the general calculation procedure for proving the durability of welded joints

\subsection{Short references}

Technical standards for proving the durability of welded joints are included within the standard series DIN EN 1993, which is called the Eurocode Program. Important calculation formulas can be found throughout the technical standards. It is difficult for students to find their way in the technical standards text. It is hard for them to select the essential, computationally relevant contents.

For this purpose, the new teaching concept crossreferences within the presentation. These cross-references enable students to find the computationally relevant formulas and rules in the technical standards.

\subsection{Open source online systems}

Open source online systems can be used either to elicit classroom feedback or to instruct peer discussion. PINGO (peer instruction for very large groups) from the University of Paderborn is used in auditorium exercises four times to connect fun, web-based, open source technology to feedback from students.

Peer instruction significantly contributes to increased system understanding of students about proving durability of welded joints (Figure 5 and Figure 6). It can be applied to different practical examples to increase system understanding.

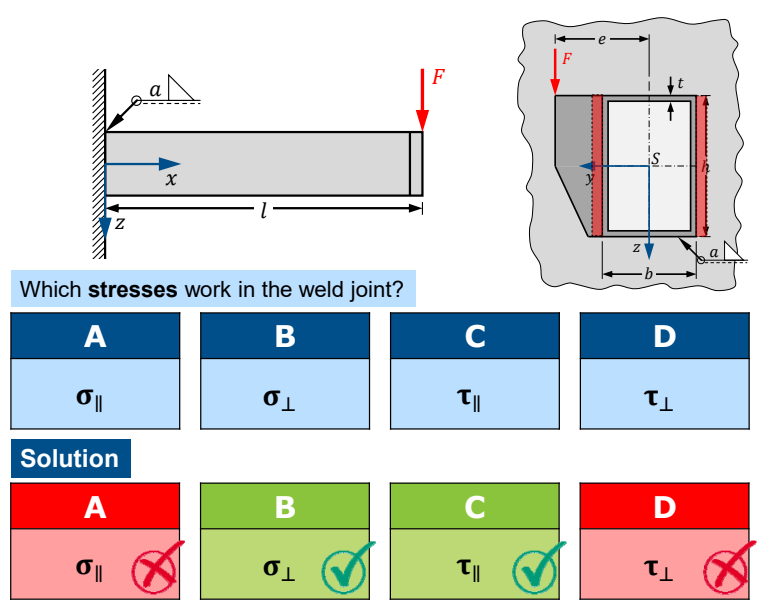

Fig. 5. Practical application example for PINGO (1) 

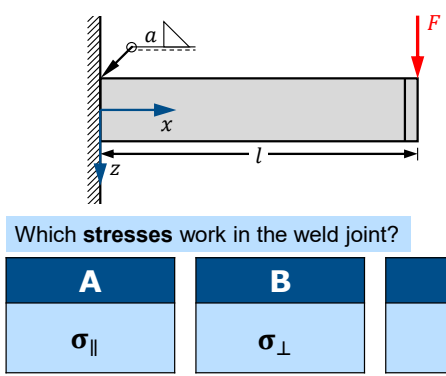

Solution
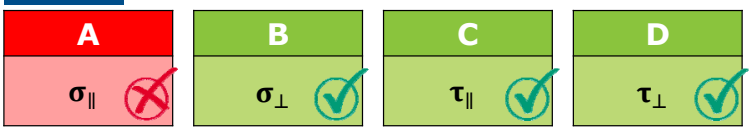

Fig. 6. Practical application example for PINGO (2)

\subsection{Gaps for Calculations}

The auditorium exercise is based on teaching slides containing gaps, as shown in Figure 7 to calculate the minimum and maximum thickness of weld joints. This allows the lecturer to address student understanding in a situation-specific manner. Calculation-specific gaps are filled during class by the lecturer writing on a tablet computer.

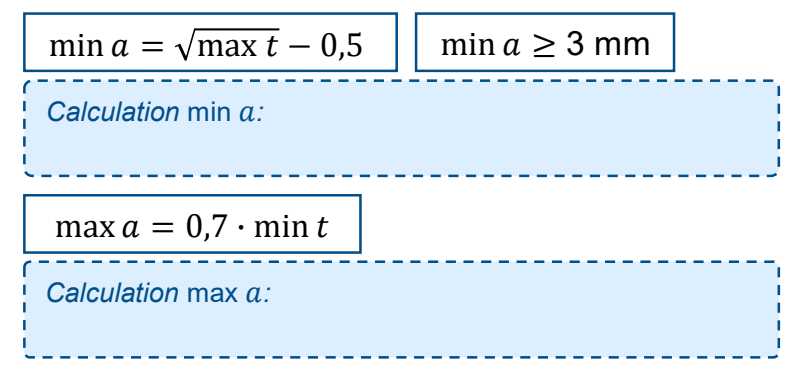

Fig. 7. Teaching slides containing gaps

\section{EXPERIENCES}

The novel learning concept was first tested in the Machine Elements and Mechatronics (MM II) unit for undergraduate students in mechanical and process engineering in their fifth semester.

The novel concept was evaluated using web-based feedback from students who actively participated in the auditorium exercise. $96.7 \%$ of the students (586 students) assessed the novel learning concept as 'very good and innovative; should be implemented more frequently in other teaching formats of undergraduate lectures'.

Besides valid learning outcomes, undergraduate students stated that the use of novel learning methods leads to significantly increased motivation and understanding of the application-oriented learning contents, according to the predefined intended learning outcomes.

Further work will show how this newly developed learning concept can also be applied in a useful way to other lectures that are held in large classrooms.

\section{References}

[1] Barbara Gross Davis, Tools for Teaching. San Francisco: Jossey-Bass, 2009 (2nd ed.). \{ISBN: 978-0-7879-6567-9\}

[2] Paul Ramsden, Learning to Teach in Higher Education. London, NY: 2nd ed. Routledge, 2003 (2nd ed.). \{ISBN: 978-0415303453\}

[3] Edward L. Deci and Richard M. Ryan, The "What" and "Why" of Goal Pursuits: Human Needs and the SelfDetermination of Behavior, Psychological Inquiry, vol. 11, no. 4 , pp. 227-268, 2000. 